\title{
The Role of Post-Conflict School Mathematics
}

\author{
Carlos Eduardo Leon Salinas and Jefer Camilo Sachica Castillo
}

We arrived at the following conclusions after discussing and thinking about the role of mathematics in school following an armed conflict:

First of all, although mathematics has been an important factor in human culture, it has not been present in schools; therefore, students' knowledge that shows mathematical practices is not taken into account. For example, measurement is a practice that responds to the procedures and forms of a social group, and the school seeks to homogenize this process, keeping in mind the management of units and instruments that sometimes do not coincide with those that are part of the daily life of the students.

In the multicultural classrooms that are occurring in the post-conflict period in Columbia, it is necessary to involve knowledge-building practices in the learning and procedures of the schools. These should be part of the policies and guidelines designed by the Colombian Ministry of Education, finding unified ways to address problems and planning designs that have student learning as a starting point. Returning to the previous example of measurement, the idea should not be to tell the student how to measure but to explore the students' ways and resources so that they can be contrasted with what the school proposes to the relationship be identified.

Secondly, it is essential to manage coexistence based on knowledge that demonstrates the necessity of comparing procedures performed by students. Post-conflict mathematics classes cannot remain individual workspaces where the communication of ideas and the discussion of points of view are not considered. In a period when eradication of the violence of Colombian society is desired, it is very

\footnotetext{
C.E. Leon Salinas $(\bowtie)$

La Gran Colombia University, Bogotá, Colombia

e-mail: carlos.leon@ugc.edu.co 
important in the classroom to form communities of practice that revolve around solving the common problems and interests of a particular group. The students are not the only actors in these groups; the idea is to create a more inclusive classroom for other actors in the academic community, such as parents and teachers in other areas of knowledge, so that the math class becomes an interdisciplinary space.

Finally, it is necessary to think of mathematics as an instrument to understand the world and not as only a purpose; that is, mathematics must be understood as knowledge that allows us to comprehend what happens in our daily lives. Mathematics classes cannot be thought of as merely places where students assimilate concepts; in the post-conflict period, it is necessary for students to understand that mathematics can help them to verify hypotheses raised in the solution of a problem or the analysis of a situation.

These are aspects of three fundamental elements in the educational proposal must have for the post-conflict mathematics class.

Open Access Except where otherwise noted, this chapter is licensed under a Creative Commons Attribution 4.0 International License. To view a copy of this license, visit http://creativecommons. org/licenses/by/4.0/. 